\title{
Biodiesel Fuel from Waste Cooking Oil: A Cheaper and Cleaner Renewable Energy Source
}

\author{
RIHAM KANAAN ${ }^{1}$, ELISSAR AL-AAWAR ${ }^{1}$, BASSAM RIACHI ${ }^{1}$, SALIM NASSREDDINE ${ }^{1}$, \\ DIANA-LUCIANA CURSARU ${ }^{2}$, JEAN CHAMOUN ${ }^{*}$ \\ ${ }^{1}$ Lebanese University, Faculty of Engineering, Chemical \& Petrochemical Engineering Department, Rafic Hariri Campus, \\ Hadath, Lebanon \\ ${ }^{2}$ Petroleum-Gas University of Ploieşti, Department of Petroleum Processing Engineering and Environmental Protection, 39 \\ Bucuresti Blvd., 100760, Ploiesti, Romania
}

\begin{abstract}
Low cost, high fatty acid content waste cooking oil was transformed into biodiesel using an acid catalyzed chemical esterification reaction with 0.5 vol. $\%$ of $\mathrm{H}_{2} \mathrm{SO}_{4}$ at $60^{\circ} \mathrm{C}$ for $1 \mathrm{~h}$ followed by the main transesterification reaction. For the purpose of comparison, biodiesel fuel was also prepared using straight vegetable oils (SVO's). The gas chromatography test showed higher than 95\% FAME (fatty acid methyl ester) content for different types of utilized feedstocks. Biodiesel fuel and its blends were characterized based on ASTM test methods to investigate its density, viscosity, flash point, pour point, heating value, and its cetane index and similar physical properties were obtained for all the prepared biodiesel fuels. $B 20$ blend, which contains $20 \mathrm{vol} . \%$ of biodiesel and $80 \mathrm{vol} . \%$ of diesel, showed a better performance than BO (100 vol.\% of diesel) when tested in a laboratory compression ignition diesel engine. After simulation of the production process via Aspen Hysys, a feasibility study was conducted and the results revealed that utilizing waste cooking oils (WCO's) as feedstock is more economical than starting with SVO's as raw material.
\end{abstract}

Keywords: Waste cooking oils, Biodiesel, Gas chromatography, Compression ignition engine, Feasibility study

\section{Introduction}

The worldwide environmental concerns regarding the emissions of greenhouse gases into the atmosphere caused mainly by the burning of fossil fuels, the increasing prices of these fuels, and the fact of their depletion in the near future, have turned the attention towards biofuels as alternative energy sources [1].

Biodiesel is a liquid biofuel characterized by its renewability, non-toxicity, biodegradability, and environmental safety. Chemically, it is a mixture of fatty acid alkyl esters that can be synthesized from either vegetable oils or animal fats via the transesterification reaction [2]. This reaction allows for obtaining a low viscosity, high cetane number biofuel that has similar properties to diesel fuel and, thus, suitable to be used in diesel engines with small or no modifications.

Nowadays, straight vegetable oils (SVOs) are the leading feedstock in industrial biodiesel production plants. However, two main concerns have urged scientists to find another potential feedstock. The first is the high production cost, which mainly accounts for the high cost of the raw material itself [3]. The second is related to the food debate concern which suggests that producing biodiesel from SVO's would decrease the oil supply as an important food ingredient [4]. This would lead to an increase in demand on raw oils, hence a significant increase in their prices will affect the selling price of the manufactured biodiesel.

A potential alternative feedstock to help overcome these obstacles is the low cost high acid content waste cooking oil. Extensive use of oil during the frying process leads to an increase in the free fatty acid content of this oil, thus making it inappropriate for further consumption by humans. Since disposing

*email: jeanchamoun76@ul.edu.lb; chamounjean@hotmail.com 
of this material would lead to serious environmental problems, such as soil pollution and underground water contamination [5], collecting these oils and processing them into biodiesel using the suitable techniques would play the role of waste minimization on one side. On the other side, it would also secure a low cost sustainable energy source.

Many reactions, such as hydrolysis, oxidation, and polymerization, which take place during the frying process are accelerated by high temperature and the presence of moisture [6]. The high free fatty acid (FFA) content of the waste cooking oil (WCO) is a result of the hydrolysis of triglycerides under the effect of frying. The presence of these acids in the transesterification media leads to soap formation [7]. Soap not only decreases the yield of biodiesel by consuming the basic catalyst, but also stabilizes the biodiesel-glycerol emulsion making their separation impossible [8].

In order to avoid the presence of the free fatty acids in the transesterification media, an acid catalyzed esterification reaction for their conversion into biodiesel is possible in the presence of methanol and the acid catalyst [9]. This chemical pretreatment step would not only solve the problem of soap formation, but would also increase the yield of the produced biodiesel.

In this study, biodiesel was prepared from various feedstocks that differ in their FFA content. These biofuels as well as their blends were characterized according to ASTM test methods and were tested in a laboratory diesel engine. An economic study was also conducted to compare the feasibility of the different biodiesel processes.

\section{Materials and methods}

\subsection{Biodiesel synthesis}

Three different types of feedstocks were investigated: fresh sunflower oil from Plein Soleil (SVO) purchased from a local supermarket, waste cooking oil collected from houses (WCO1) as well as from local restaurants (WCO2). Other chemicals include methanol (Sigma-Aldrich, 99.8\%), sulfuric acid (Sigma-Aldrich, 99.999\%), potassium hydroxide (Sigma-Aldrich, 85\%), distilled water, silica (SigmaAldrich, 99.8\%), aniline (Sigma-Aldrich, 99.5\%), standard FAME $\mathrm{C}_{16}-\mathrm{C}_{18}$ mixture \#1 from RESTEK and diesel (CORAL). The reactions took place in a $250 \mathrm{~mL}$ round bottom flask using a hot plate for stirring and heating purposes.

In order to identify the chemical reactions involved for the transformation of each type of feedstock, the free fatty acid content of each oil was determined by performing a titration test where $50 \mathrm{~mL}$ of isopropanol are added to $10 \mathrm{~g}$ of WCO and few drops of phenolphthalein (coloring indicator). The sample was then titrated with $1 \mathrm{M}$ sodium hydroxide $\mathrm{NaOH}$. The volume of $\mathrm{NaOH}$ added drop by drop is recorded when the color changes from colorless to violet. FFA \% is then calculated according to equation 1.

$$
\% \mathrm{FFA}=\frac{\mathrm{Vs} \times \mathrm{C} \times 28.2}{\mathrm{~m}}
$$

where: $\mathrm{Vs}=$ volume of the $\mathrm{NaOH}$ added to reach equivelance $(\mathrm{mL})$,

$\mathrm{C}=$ concentration of $\mathrm{NaOH}$ used $(0.1 \mathrm{~mol} / \mathrm{L})$,

$\mathrm{m}=$ mass of the sample $(10 \mathrm{~g})$

Having less than 3 wt.\% of FFA, fresh sunflower oil (SVO) and WCO1 are converted into biodiesel through a direct transesterification reaction [10] which is a base catalyzed $(\mathrm{KOH})$ reaction between the oil and methanol, where molar methanol: oil ratio is $6: 1,1 \mathrm{wt} \% \mathrm{KOH}$, temperature of $60^{\circ} \mathrm{C}$ and a reaction time of $2 \mathrm{~h}[11]$.

WCO2 with higher than 3 wt.\% of FFA is first filtered to remove all insoluble particles that may cause common engine problems if they persist. Followed by the physical pretreatment, is the acid catalyzed esterification of the free fatty acids in WCO's into biodiesel using the operating conditions reported elsewhere [12] of 4:1 molar methanol to $\mathrm{WCO}$ ratio, $45^{\circ} \mathrm{C}, 0.5 \mathrm{vol} . \% \mathrm{H}_{2} \mathrm{SO}_{4}$, and a reaction time of $1 \mathrm{~h}$. After the reaction, the mixture was allowed to settle for $8 \mathrm{~h}$ and excess alcohol, with $\mathrm{H}_{2} \mathrm{SO}_{4}$ 
and impurities, moved to the top layer, which was removed in a separating funnel while the bottom was moved to the transesterification reaction.

The main transesterification reaction took place using the operating conditions reported in a previous study [11], after which products are left to settle overnight in order to separate into a higher density phase containing mainly glycerol and a lower density phase containing mainly biodiesel.

The purification step includes water washing of biodiesel by slightly acidic hot water $\left(5 \mathrm{~mL}\right.$ of $\mathrm{H}_{2} \mathrm{SO}_{4}$ per liter) after which the water is discarded and biodiesel is dried overnight over a thin layer of silica. Then, the biodiesel fuel is filtered through the accelerated Buchner funnel.

\subsection{Analysis of raw material, biodiesel, and blends}

\subsubsection{Raw material characterization}

Two important parameters that allowed to investigate the efficiency of the transesterification reaction were tested, the density and the viscosity of the different types of feedstock.

The densities of the samples were determined by measuring their API according to ASTM D287 through the use of a standard hydrometer. The method consisted of filling a standard graduated cylinder with the sample and then inserting the hydrometer. The hydrometers designed to float upright on the liquid whose API gravity is being studied. Equation (2) was used to convert from API into specific gravity. The densities were further calculated with reference to water $\left(1000 \mathrm{~kg} / \mathrm{m}^{3}\right)$.

$$
\text { API gravity }=\frac{141.5}{\text { specific gravity }}-131.5
$$

The kinematic viscosity is determined by using a Saybolt Viscometer from Koehler consisting of a microprocessor based bath for accurate temperature control. The method requires determining the time required for $60 \mathrm{~mL}$ of the sample to pass through a specific orifice as advised in ASTM D88. The time is recorded in seconds and the viscosity is reported in Saybolt Universal Seconds and then converted into centistokes units [13].

\subsubsection{Gas Chromatography: GC}

In order to determine the FAME \% in each biodiesel sample, a GC (Agilent) 7890B series with a flame ionization detector at a temperature of $250^{\circ} \mathrm{C}$ and a CP 9080: $(30 \mathrm{~m}, 0.32 \mathrm{~mm}, 0.25 \mu \mathrm{m})$ column was used. Isothermal oven temperature of $210^{\circ} \mathrm{C}$, in a splitless mode inlet at $250^{\circ} \mathrm{C}$ and $1 \mathrm{~mL} / \mathrm{min}$ of Nitrogen gas were employed. Vials were prepared using W g of the sample dissolved in $10 \mu \mathrm{L}$ of internal standard (C17) solution $(0.2252 \mathrm{mg} / \mathrm{mL}$ of $\mathrm{C} 17$ in heptane). The FAME \% was determined using the following equation:

$$
\text { FAME } \%=\frac{\sum \mathrm{A}}{\mathrm{A}_{\mathrm{IS}}} \times \frac{\mathrm{C}_{\mathrm{IS}} \times \mathrm{V}_{\mathrm{IS}}}{\mathrm{W}} \times 100
$$

where, $\Sigma \mathrm{A}$ is the total peak area of the methyl esters, $\mathrm{A}_{\text {IS }}$ is the area of the internal standard, $\mathrm{C}_{\text {IS }}$ and $\mathrm{V}_{\text {IS }}$ represent the internal standard concentration $(\mathrm{mg} / \mathrm{mL})$ and volume $(\mathrm{mL})$ respectively and $\mathrm{W}$ is the weight of the biodiesel sample (in $\mathrm{mg}$ ).

\subsubsection{Other characterization tests for biodiesel-petro diesel blends}

The densities and viscosities of all samples were determined following the same method used for characterizing raw materials.

The flash point is defined as the lowest temperature at which application of an ignition source causes the vapors of the sample to ignite. The test method is performed following ASTM D93 utilizing Koehler automatic Pensky-Martens closed cup flash point tester. A brass test cup is first filled with the tested sample. Once the test position is selected, the apparatus will automatically start testing for the flash point by progressive heating and dipping of a flame into the sample. If a flash occurs, it will be directly detected by the sensor provided by the apparatus and displayed on the screen. 
The pour point of a petroleum product is the lowest temperature at which movement of a sample is observed under prescribed conditions. As advised by ASTM D97 and utilizing a pour point bath from Koehler, the tested sample is poured into a test jar with a cork carrying a thermometer and then placed in the cooling bath. The mobility of the sample is continuously checked as it cools until the pour point is detected.

The heating value is defined as the amount of heat released by burning of a unit mass of the fuel. It is determined as advised in ASTM D240 using a bomb calorimeter from Koehler equipped with a watercooling system. The sample is weighed over an analytical balance, the bomb set up is prepared, and pressurized oxygen is introduced into the chamber where combustion proceeds.

The cetane index is determined by measuring the aniline point of each sample using the automatic aniline point apparatus from Koehler following ASTM D611-04. The method consists of mixing equal volumes $(10 \mathrm{~mL})$ of aniline and the sample and then pouring the mixture into a test jar placed in a heating bath. Heating and stirring are applied until the two phases become miscible after which the mixture is allowed to cool down. The first cloud point is recorded as the aniline point of the sample. The cetane index is then calculated by applying equation (4):

$$
\text { Cetane index }=\frac{\text { aniline point }\left({ }^{\circ} \mathrm{F}\right) \times \text { API gravity }}{100}
$$

\subsection{Evaluation of an engine performance: B20 vs. B0}

Experimental studies were conducted in order to evaluate the performance of a laboratory compression ignition diesel engine including measurement of torque, specific fuel consumption, and the gas emissions versus the speed of the engine (RPM) when utilizing pure diesel and a B20 blend as fuels.

The used diesel engine is a four stroke direct injection engine, designed by the German Company "FARYMAN DIESEL". It is built as a single cylinder with vertical configuration and it employs a watercooled system. Other engine specifications are presented in Table 1.

The engine is connected to a gas analyzer from WITT, fitted on the exhaust stream in order to measure the level of emissions of gas leaving the combustion chamber in the exhaust. The measured emissions include carbon monoxide and carbon dioxide.

Table 1. Engine specifications

\begin{tabular}{|c|c|}
\hline Parameter & Specification \\
\hline Model & $18 \mathrm{~W}$ \\
\hline Number of cylinders & 1 \\
\hline Maximum power @ 3000 rpm $(\mathrm{kW})$ & 4.76 \\
\hline Stroke $(\mathrm{mm})$ & 55 \\
\hline Maximum speed & 3600 \\
\hline Compression ratio & $20: 1$ \\
\hline
\end{tabular}

The equations used to generate the performance curves of a diesel engine are:

$$
\begin{aligned}
& \text { Torque }(\mathrm{N} . \mathrm{m})=\text { Load }(\mathrm{N}) \times \text { arm length }(\mathrm{m}) \\
& \text { Power }(\mathrm{kW})=\frac{\text { Speed }\left(\frac{\mathrm{rd}}{\mathrm{s}}\right) \times \text { Torque }}{1000} \\
& \text { Fuel rate }(\mathrm{ml} / \mathrm{s})=\frac{10}{\text { Fuel depletion time }\left(\frac{\mathrm{s}}{10 \mathrm{ml}}\right)} \\
& \text { Fuel Consumption }(\mathrm{g} / \mathrm{kWh})=\frac{\text { fuel rate } \times 3.6}{\text { Power }} \times \rho_{\text {fuel }}
\end{aligned}
$$




\subsection{Simulation of biodiesel production plant}

In order to evaluate the biodiesel production process on industrial scale using the obtained laboratory results, this process is modeled via Aspen HYSYS software V8.6 and the model developed by the authors of this paper is shown in Figure 1. A production rate of $1,126 \mathrm{~kg} / \mathrm{h}$ biodiesel was obtained, which is enough to sustain the needs of the Lebanese transportation sector based on a blending factor of $20 \%$. The production process constitutes three main steps: pretreatment, main reaction, and purification. The pretreatment section consists of a physical and a chemical step. The physical pretreatment is represented by a solid separator to remove any food particles that may persist in the fuel, if not treated. The chemical pretreatment involves an acid catalyzed esterification reaction carried out in a CSTR-100. As for the main reaction, it is a base catalyzed transesterification reaction which is also carried out in a CSTR-101 followed by the methanol recovery section where the mixture is heated to above the boiling point of methanol and then flashed. Finally, the purification of biodiesel consists of water washing and drying over a thin layer of silica before the final filtration by using another solid separator. Table 2 lists the different units used in the simulation shown in Figure 1.

Table 2. List of simulation units

\begin{tabular}{|c|c|}
\hline Unit's Name in the flowchart & Type of the unit \\
\hline X-100, X-103 & Solid separator \\
\hline E-100, E-102, E-104 & Oil heater \\
\hline CSTR-100, CSTR-101 & Continuously stirred tank reactor \\
\hline X-101, X-102 & Gravity settler \\
\hline P-100 & Pump \\
\hline V-100 & Flash separator \\
\hline MIX-100, MIX-101 & Mixer \\
\hline
\end{tabular}

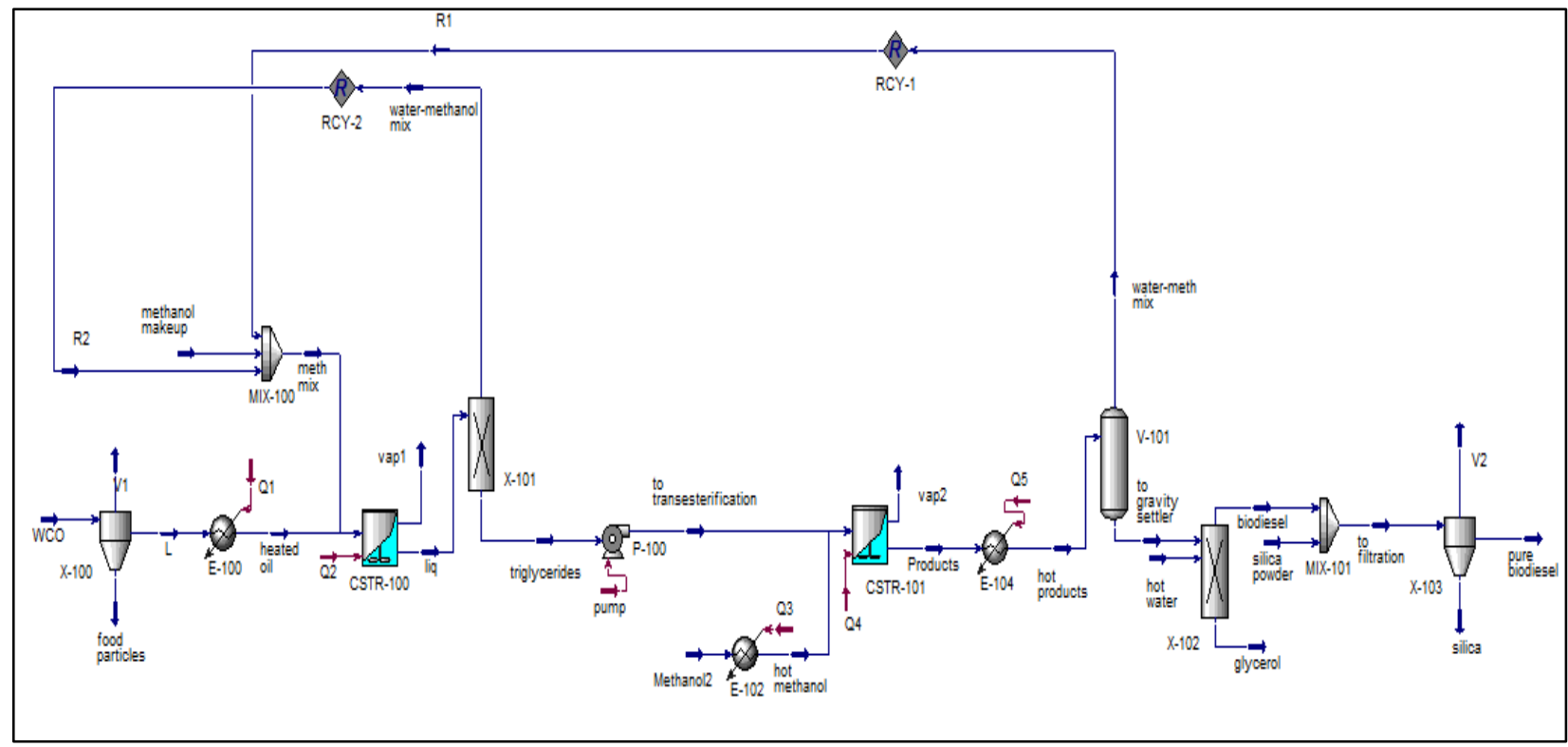

Figure 1. Biodiesel Production Process

The physical and chemical pre-treatment steps are neglected when producing biodiesel from SVO's. As for WCO1, only the chemical esterification step is neglected. 


\section{Results and discussions}

\subsection{FFA content}

The results obtained after titrating the waste oil samples against sodium hydroxide solution are presented in Table 3.

Table 3. FFA content results

\begin{tabular}{|c|c|c|c|c|}
\hline Feedstock & 1st titration & 2nd titration & Average FFA \% & $\begin{array}{c}\text { Chemical pretreatment } \\
\text { required }\end{array}$ \\
\hline WCO1 & 1.400 & 1.420 & 1.410 & No \\
\hline WCO2 & 5.390 & 5.410 & 5.400 & Yes \\
\hline
\end{tabular}

The waste cooking oil collected from restaurants (WCO2) has a FFA content of $5.4 \%(>3 \%)$ meaning that this feedstock needs to be chemically pre-treated to decrease its fatty acid content in order to enhance the efficiency of the transesterification reaction and reduce soap formation. As for the waste oil collected from houses (WCO1), no chemical esterification is required.

\subsection{Physical properties of raw material}

The densities and viscosities of the various types of feedstock as well as their corresponding biodiesel fuels are represented in Figures 2 and 3.

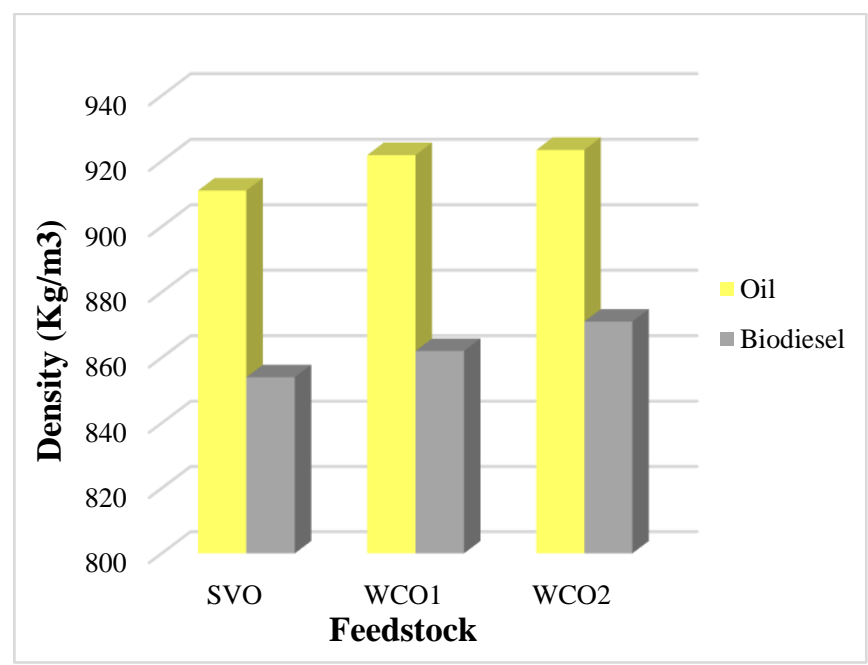

Figure 2. Density results

Figure 2 shows that as the oil switches from SVO to waste oil, its density also increases gradually. A simple explanation for these results would be the polymerization reactions that will take place at high temperatures, leading to the formation of the higher density oligomeric and polymeric products. This effect is more pronounced for higher reaction time when the oil is extensively used and for longer periods of time as it is the case for the waste restaurant oil having the highest density.

Another obvious result is the decrease in the densities of the biodiesel produced from their corresponding higher densities oils, due to structural changes taking place as a result of trans-esterification proving the efficiency of this reaction.

The final result presented in Figure 2 shows that the higher density oil also produces a higher density biodiesel, since both the oil and its corresponding biodiesel have the same fatty acid composition. 


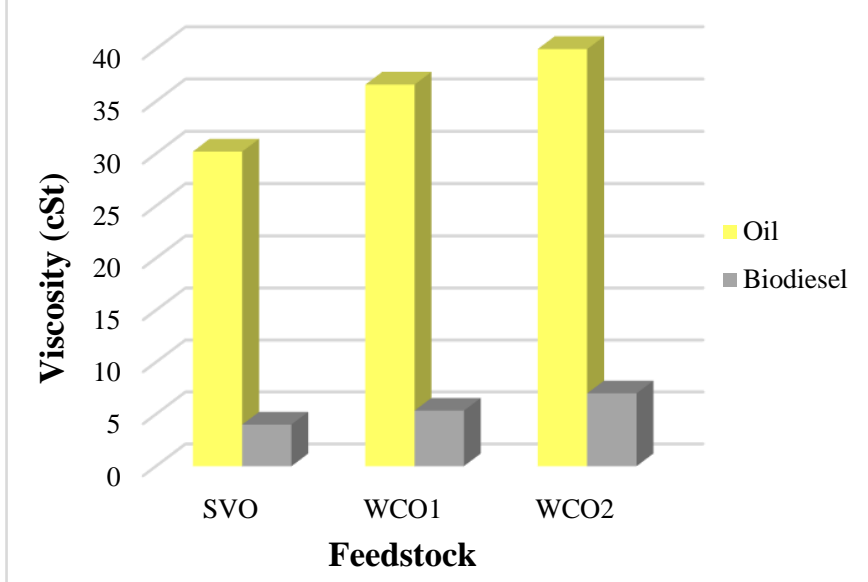

Figure 3. Viscosity results

The results show that the more the waste oil is used, the higher its viscosity. Just like in the case for densities, the increase in viscosity is directly related to the occurrence of the polymerization reaction accelerated by the higher temperatures and the longer reaction times.

A significant reduction in the viscosities of the waste oils after transesterification reaction takes place. This decrease in viscosity is mainly due the transformation of the more viscous component, triglyceride, in to the lower viscosity component, FAME.

The same composition of fatty acid chains (same molecular weight and degree of saturations) in both the triglycerides and the corresponding biodiesel makes it obvious that the higher viscosity oil would produce the higher viscosity biodiesel.

\subsection{FAME yield \& biodiesel composition}

Figure 4 shows a FAME content higher than $95 \%$ for all the biodiesel fuels prepared from the various feedstocks, which fairly conform to the EN norms with minimum ester content of $96.5 \%$ (EN 14214, 2008). Other impurities in the biodiesel fuel include unreacted oil, unreacted methanol, water, and glycerol resulting from imperfections in separation

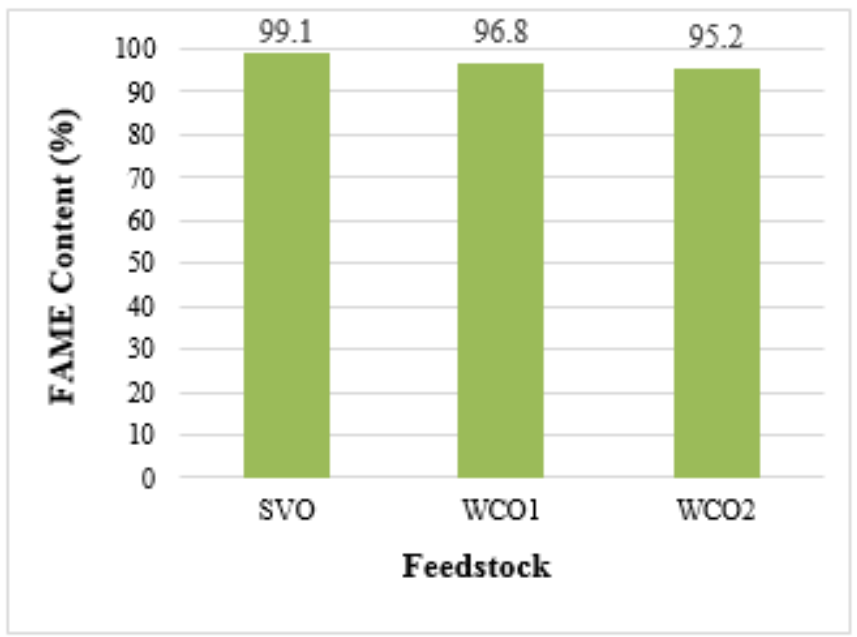

Figure 4. FAME content for all prepared biodiesel fuels

The analysis of the chromatograms (Figures 5, 6 and 7) obtained for all types of the biodiesel fuels prepared allows for determining the composition of these fuels. 
Figure 5 presents the chromatogram of a biodiesel fuel prepared from fresh sunflower oil as feedstock. The figure shows that the corresponding biodiesel contains the highest share of methyl linoleate ester, with no methyl linolenate ester content. This result is due to the fact that fresh sunflower oil usually contains $60-70 \mathrm{wt}$. \% of linoleic acid.

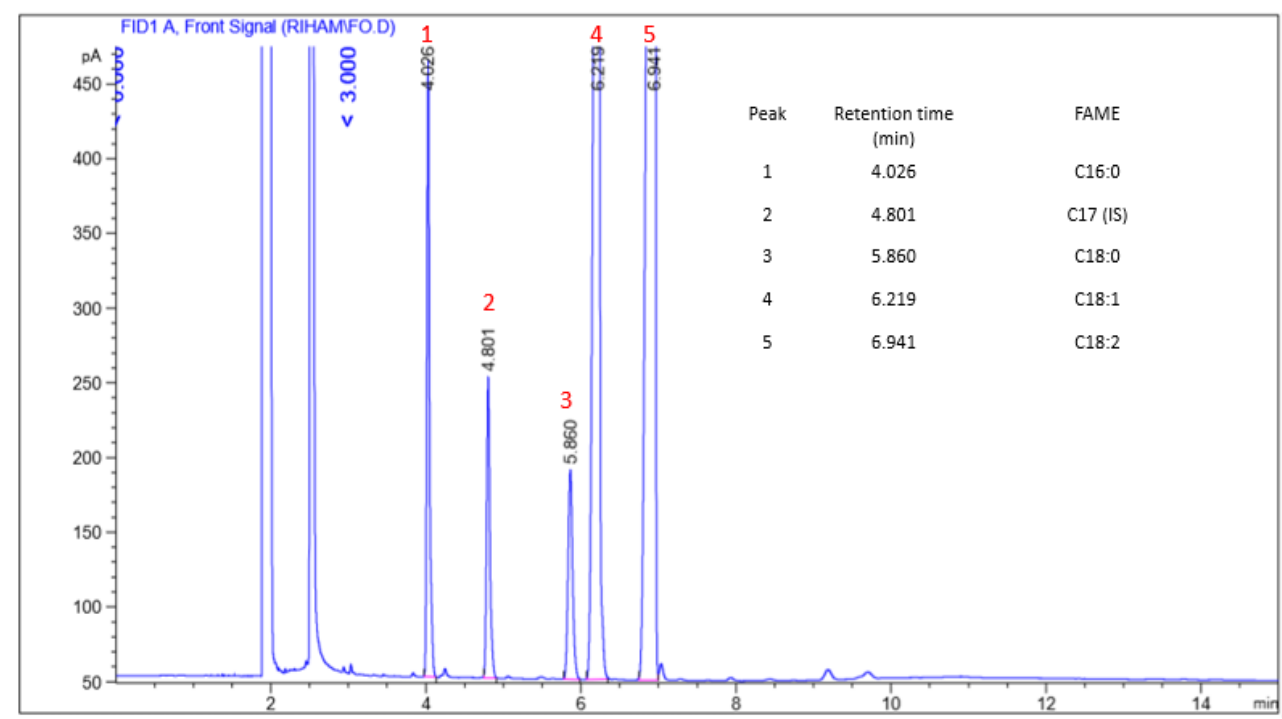

Figure 5. Chromatogram for biodiesel prepared from SVO

For WCO1, the biodiesel fuel also contains the highest share of methyl linoleate and no methyl linolenate ester because the SVO and the WCO1 are both of sunflower origin, containing the highest percentage of linoleic acid.

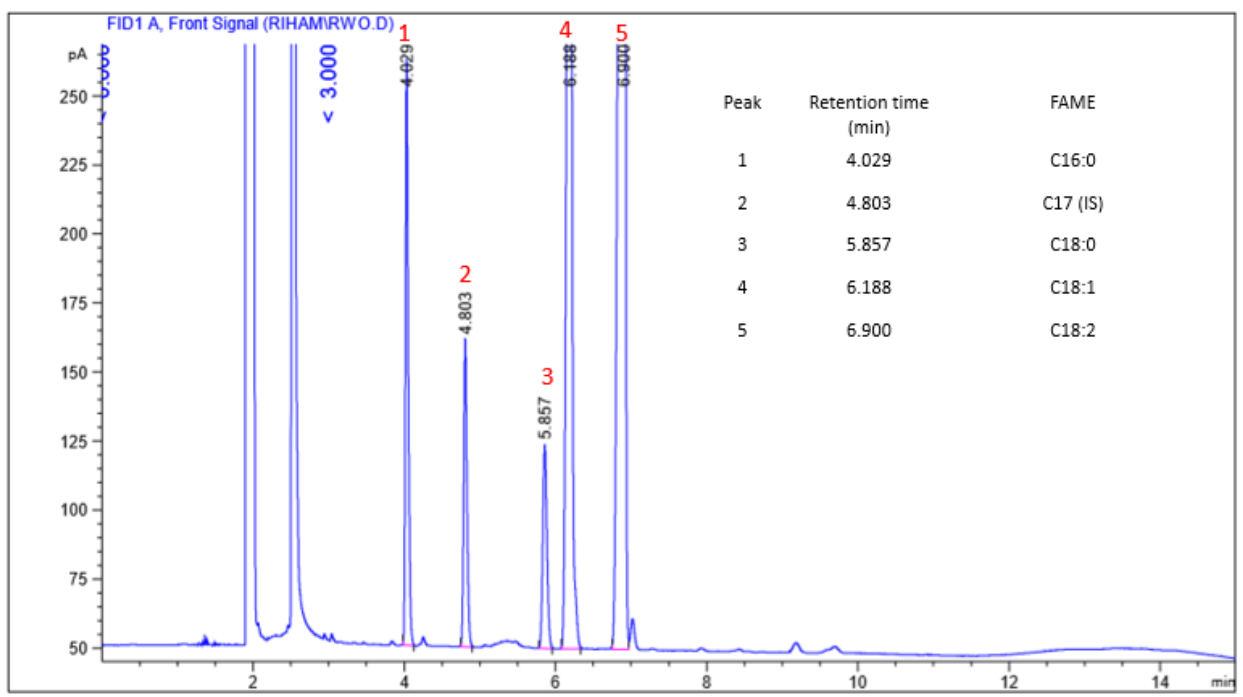

Figure 6. Chromatogram for biodiesel prepared from WCO1

By comparing the chromatogram of this fuel to that of the standard mixture, it is obvious that the biodiesel fuel prepared from WCO2 shows the presence of cis and trans isomers for methyl oleate and methyl linoleate esters, as presented in Figure 7. The results also show that this type of biodiesel contains a significant amount of methyl linolenate ester, which indicates that the original oil sample contains a certain quantity of linolenic acid unlike the SVO and the residential waste cooking oils. 


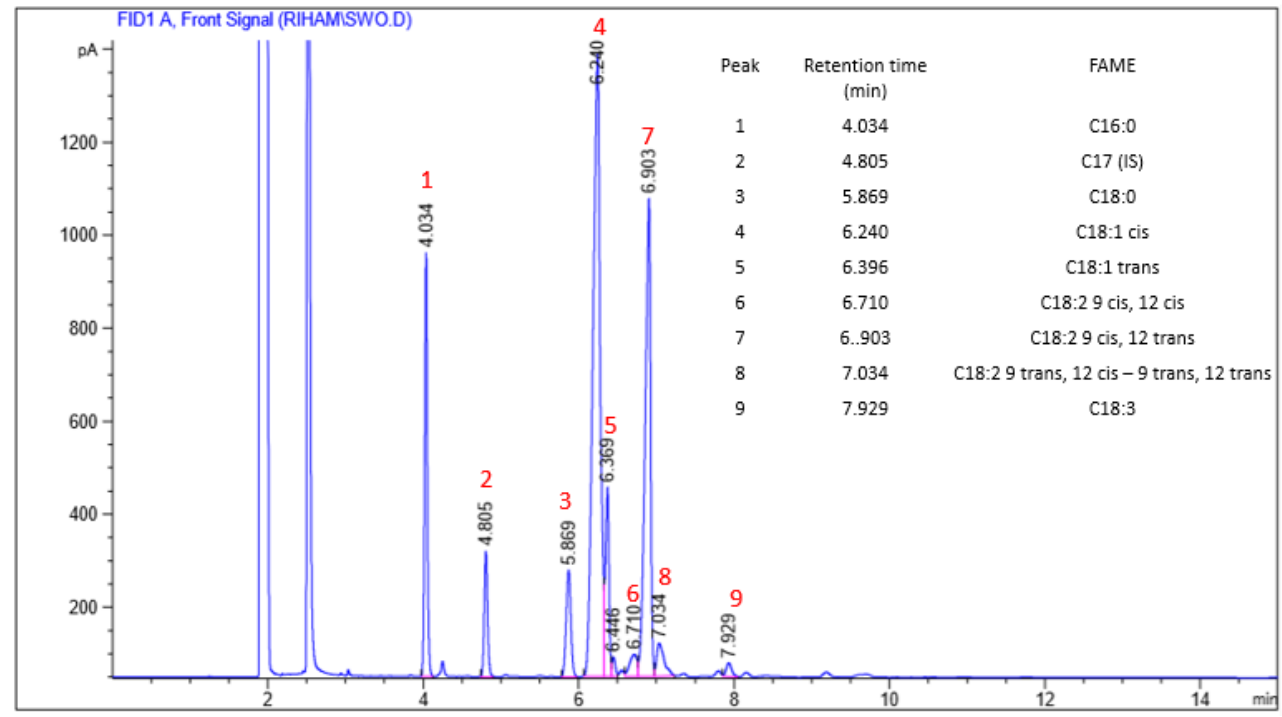

Figure 7. Chromatogram for biodiesel prepared from $\mathrm{WCO} 2$

The biodiesel fuels are composed of methyl palmitate, methyl stearate, methyl oleate, methyl linoleate and methyl linolenate esters with their corresponding isomers. As shown in Figure 8, the biofuels prepared from SVO and WCO1 show almost the same composition with methyl linoleate ester occupying the highest share of all methyl esters due to the previously explained reasons. However, a different composition was obtained for the biodiesel prepared from WCO2 due to the different origins of the feedstock.

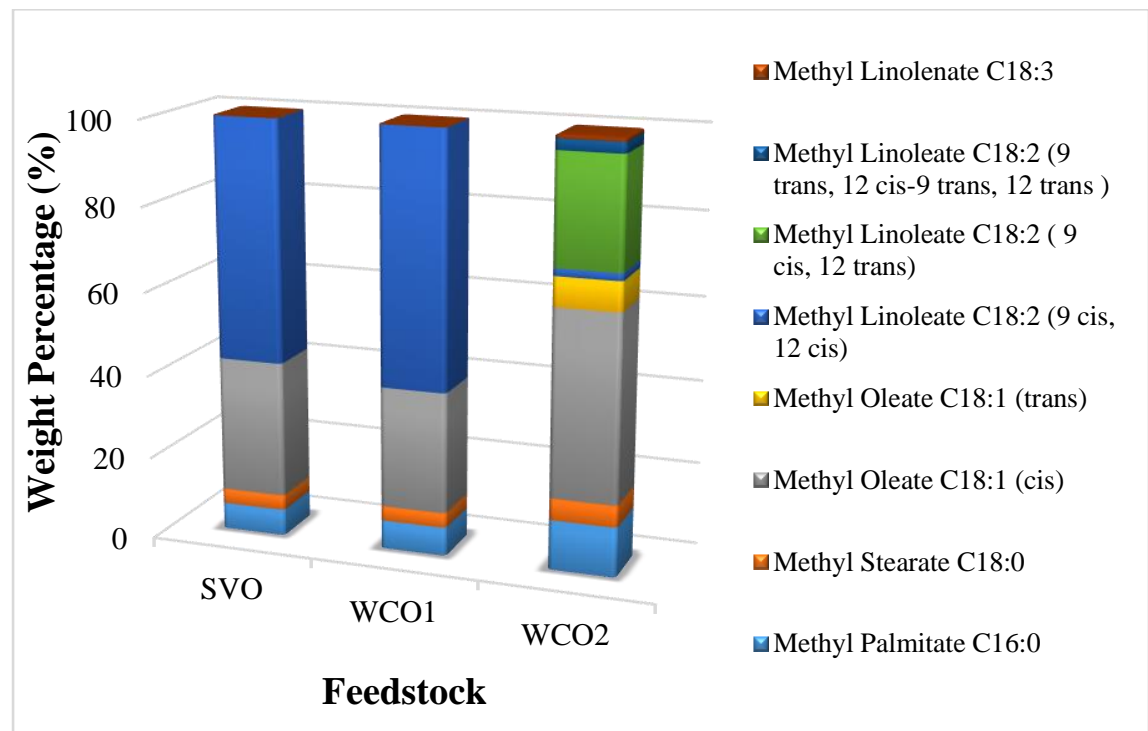

Figure 8. Comparison of the FAME distribution in all biodiesel fuels

\subsection{Physical-chemical properties of biodiesel \& biodiesel blends}

Different tests were performed in order to validate the compatibility of biodiesel fuels as well as biodiesel -petro diesel blends according to ASTM standards. In addition, different tests were performed to study the effect of blending on the prepared biofuels. Figure 9 shows that as the blending factor increases, the density of the mixture increases due to the higher density of the biodiesel resulting in lower fuel consumption. The viscosity of the blend also increases as the blending factor increases, as shown in Figure 9, resulting in higher pumping costs as well as the possibility of plugging of engine components. The flash point and pour point of the blends also increase with the blending factor. This results in safer conditions, on one hand, and in possible engine damage by freezing on the other hand. Lower engine 
efficiency is obtained as the blending factor increases due to the decrease in the calorific values of the fuels, as depicted in Figure 9 thus resulting in lower engine efficiency. As for the cetane indices for all the B20 blends, the results conform to the specifications imposed by ASTM D975 with a minimum cetane index of 40 for any fuel to be used in diesel engines.

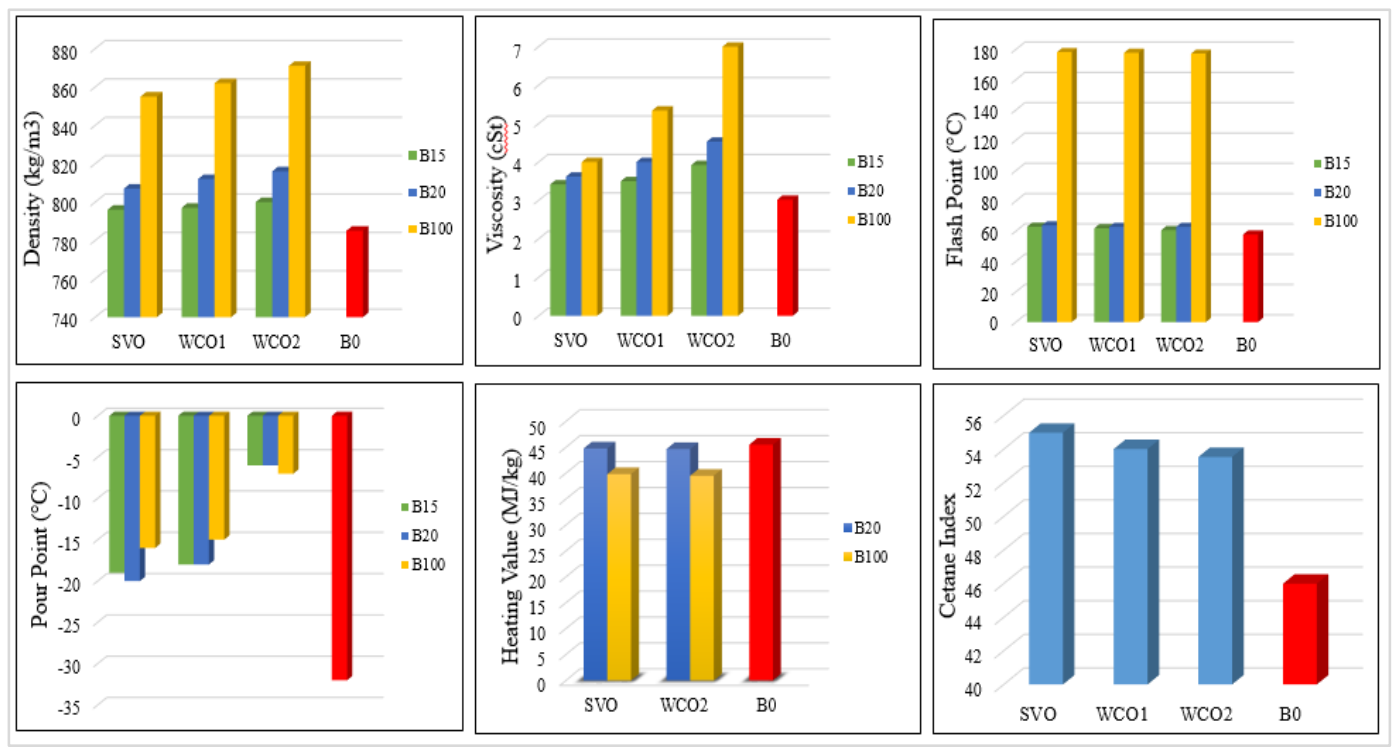

Figure 9. Physical-Chemical characteristics of biodiesel and blends

All the results obtained conform to the specifications imposed by the ASTM standards on biodiesel fuel and its blends. By taking the biodiesel produced from SVO as reference, the percentage in deviation of all the physical properties was calculated for WCO1 and WCO2. The deviations were less than $10 \%$, except for the viscosity of WCO2 ( 25\%), which means that similar physical properties are observed for all types of synthesized biodiesel fuels. This allows for concluding that WCO's can be used as a potential feedstock to produce biodiesel with properties that are conforming to the ASTM standards and European norms and similar to that produced from straight vegetable oils.

\subsection{Performance curves of a $\mathrm{CI}$ engine}

The performance curves of a compression ignition (CI) diesel engine are shown in Figure 10. Three tests were carried out to prove the fidelity of the obtained results and the average of the results are displayed. The parameters include torque, specific fuel consumption, and the carbon emissions versus the engine speed (rpm). B20 and B0 fuels are tested for comparison purposes.

Figure 10 shows that the speed at which maximum torque is obtained for both cases is $2800 \mathrm{rpm}$. The same power output is obtained for both fuels over the same speed range since the lower calorific value of biodiesel is compensated by its higher density.

The fuel consumption curve for a B20 blend is shifted to above that of pure diesel in the region of the operating nominal speed of the engine $(2500 \mathrm{rpm}<$ Speed $<3500 \mathrm{rpm})$ because a higher density means higher required mass injected for the same volume injected.

B20 blend shows a $70 \%$ reduction in the carbon monoxide emissions and a reduction of $34 \%$ in the carbon dioxide gas experimentally proving that biodiesel is a more environmentally friendly fuel. The reduction in $\mathrm{CO}$ emissions is related to the more complete combustion due to the presence of oxygen in the chemical structure of biodiesel. The reduction in carbon dioxide emissions is related to the lower carbon content of biodiesel $\left(\mathrm{C}_{16}-\mathrm{C}_{18}\right)$ fuel as compared to that for diesel $\left(\mathrm{C}_{13}-\mathrm{C}_{25}\right)$. 


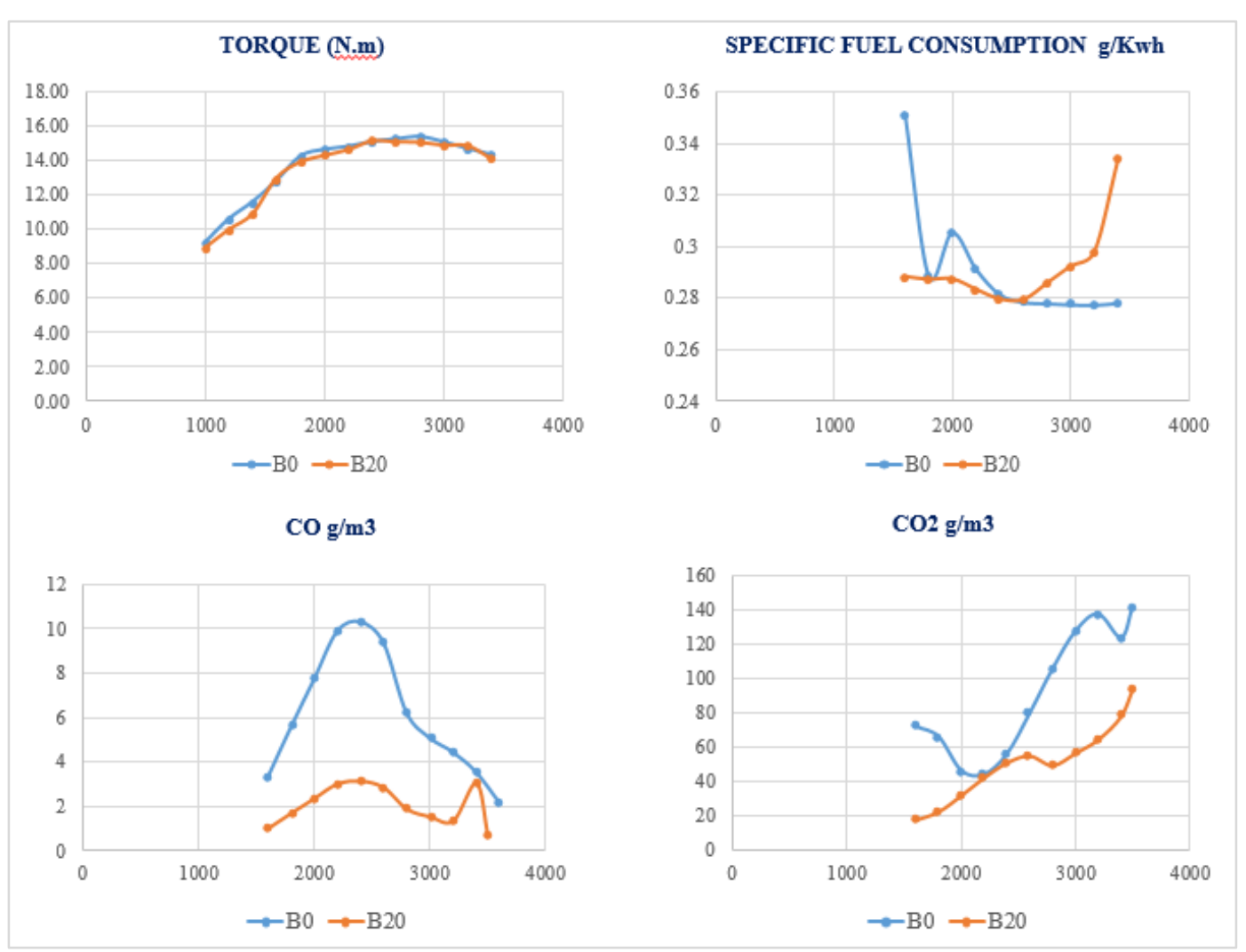

Figure 10. Comparison of engine performance curves for B0 \& B20 fuels

\subsection{Economic evaluation}

An economic study was conducted in order to evaluate the feasibility of all biodiesel production processes. The negative cash flows are represented by the fixed and operating costs, while the positive cash flows resemble the profits from selling the products. Fixed capital costs include purchasing the equipment, installing them, and purchasing the land. The operating costs include raw material, energy, labor, maintenance and miscellaneous costs. The costs are presented in Tables 4 and 5. The cost of the equipment are based on a previous study [14] and by taking into account the Chemical Engineering Plant Cost Index (CEPCI). The land cost estimation is obtained from land prices in Lebanon [15]. The piping cost resembles $15 \%$ of the total cost of the equipment [16], the labor costs are based on a plant in Wisconsin, USA [17], the energy costs are calculated by taking the duties of the equipment provided by Aspen Hysys and then by using the average price of energy in Lebanon, which is 5.29 cent $/ \mathrm{kWh}$ [18], the maintenance cost represents $10 \%$ of the equipment initial costs, the raw materials costs and profits are calculated by considering the flow rates required and the prices shown in Table 3. Finally, the miscellaneous costs resemble $10 \%$ of the yearly raw materials costs [17].

By examining the two tables, it is obvious that the capital cost for the $\mathrm{WCO} 2$ process is the highest due to the need of purchasing and installing additional equipment as compared to the other processes. Energy costs for this process are also the highest among the analyzed ones and this result is explained by the need of additional chemical pretreatment steps leading to an increase in the operating costs. However, this increase is compensated by the decrease in the cost of the raw material as it is waste oil.

Table 4. Prices of involved chemical species [14]

\begin{tabular}{|c|c|}
\hline Type of Commodity & Price (\$/ton) \\
\hline Vegetable Oil & 400 \\
\hline Waste Cooking Oil & 100 \\
\hline KOH (Catalyst) & 740 \\
\hline
\end{tabular}




\begin{tabular}{|c|c|}
\hline Methanol & 400 \\
\hline Biodiesel & 1230 \\
\hline Glycerol & 3000 \\
\hline $\mathrm{H}_{2} \mathrm{SO}_{4}$ & 280 \\
\hline
\end{tabular}

Table 5. Estimation of fixed costs for all processes [14]

\begin{tabular}{|c|c|c|c|}
\hline & \multicolumn{3}{|c|}{ Estimated capital cost (in \$) } \\
\hline Investment type & SVO & WCO1 & WCO2 \\
\hline Reactors & 91,000 & 91,000 & 154,400 \\
\hline Storage tanks & 38,000 & 38,000 & 38,000 \\
\hline Flash separators & 120,000 & 120,000 & 120,000 \\
\hline Heaters & 173,606 & 173,606 & 345,521 \\
\hline Pump & 3,000 & 3,000 & 3,000 \\
\hline Mixers & 5,000 & 5,000 & 5,000 \\
\hline Filter & 24,000 & 48,000 & 48,000 \\
\hline Pipes & 63,369 & 66,969 & 104,979 \\
\hline Land + Construction & $1,000,000$ & $1,000,000$ & $1,000,000$ \\
\hline Total investment cost & $\mathbf{1 , 5 1 7 , 9 7 5}$ & $\mathbf{1 , 5 4 5 , 5 7 5}$ & $\mathbf{1 , 8 1 8 , 9 0 0}$ \\
\hline
\end{tabular}

Table 6. Operating costs for all biodiesel production processes

\begin{tabular}{|c|c|c|c|}
\hline & \multicolumn{3}{|c|}{ Cash Flow (in \$) } \\
\hline Type of Operation & SVO & WCO1 & WCO2 \\
\hline Labor & 325,500 & 450,000 & 500,000 \\
\hline Energy & $4,150,111$ & $5,620,111$ & $5,910,000$ \\
\hline Raw Materials & $8,046,576$ & $5,914,576$ & $6,132,129$ \\
\hline Maintenance & 42,246 & 44,646 & 69,986 \\
\hline Miscellaneous & 804,658 & 591,458 & 613,213 \\
\hline Total Revenue & $13,758,480$ & $13,758,480$ & $13,758,480$ \\
\hline Net Balance & $\mathbf{3 8 9 , 3 8 9}$ & $\mathbf{1 , 1 3 7 , 6 8 9}$ & $\mathbf{5 3 3 , 1 5 2}$ \\
\hline
\end{tabular}

The net present value (NPV) and the payback period (PBP) for all above-mentioned processes are also calculated. Figure 11 and 12 show that all these processes are feasible. However, looking at WCO, it appears more economical. The high capital and operating costs involved in WCO processes are overcome by the lower costs of waste oil as compared to SVO. 


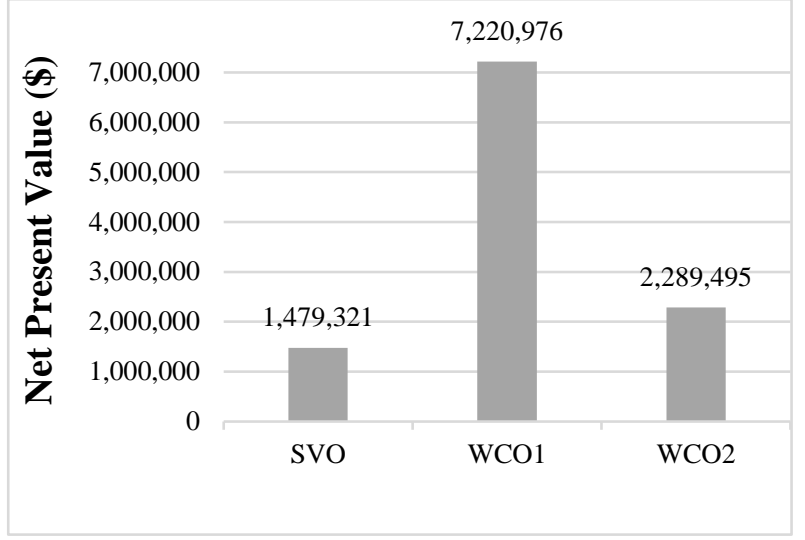

Figure 11. Comparison of NPV for all analyzed processes

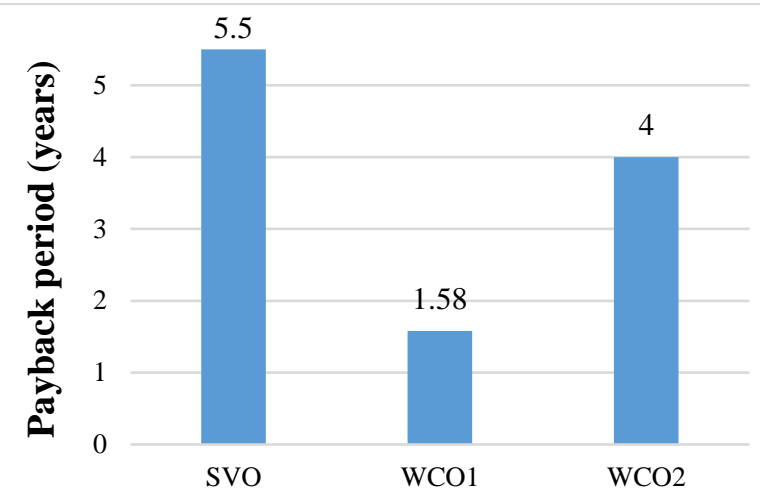

Figure 12. Comparison of PBP for all analyzed processes

\section{Conclusions}

High fatty acid content of WCO were successively converted into biodiesel via a two-step catalytic process with a FAME content of more than $95 \%$. The physical-chemical properties of this biodiesel, as well as its blends, are conformed to the specifications imposed by the ASTM standards and European norms. These results were also similar to the biodiesel synthesized from straight vegetable oil as feedstock. This means that the acid pretreatment followed by the base catalyzed reaction of WCO is a viable process for biodiesel production and as well diminishes the energy crises and environmental pollution issues. The feasibility study revealed that beginning with WCO to produce biodiesel (NPV = $2,289,495$ \$ \& PBP = 4 years) is more economical than beginning with straight vegetable oils. The higher capital, operating and energy cost involved in the WCO processes due to the need of additional processing equipment in the pretreatment steps is overcome by the very low cost of the WCOs as compared to the high cost of SVOs.

\section{References}

1. PHAN, A.N., PHAN, T.M., Biodiesel Production from Waste Cooking Oils, Fuel, 87(17-18), 2008, 3490-3496. https://doi.org/10.1016/j.fuel.2008.07.008

2. MOSER, B., Biofuels, Springer, New York, 2010, 285-347.

https://doi.org/10.1007/978-1-4419-7145-6_15

3. PREDOJEVIC, Z.J., The production of biodiesel from waste frying oils: A comparison of different purification steps, Fuel, 87(17-18), 2008, 3522-3528.https://doi.org/10.1016/j.fuel.2008.07.003

4. JAVIDIALESAADI, A., RAEISSI, S., Biodiesel Production from High Free Fatty Acid-Content Oils: Experimental Investigation of the Pretreatment Step, APCBEE Procedia, 5, 474-478.

https://doi.org/10.1016/j.apcbee.2013.05.080 
5. VINYES, E., OLIVER-SOLA, J., UGAYA, C., RIERADEVALL, J., GASOAL, C.M., Application of LCSA to used cooking oil waste management, The International Journal of Life Cycle Assessment, 18(2), 2013, 445-455. http://dx.doi.org/10.1007/s11367-012-0482-z

6. ALIREZA, S., Tan, C.P., MIRHOSSEINI, H., CHE MAN, Y.B., Effect of frying process on fatty acid composition and iodine value of selected vegetable oils and their blends, International Food Research Journal,17(2), 2010, 295-302.

7. RINCON, L.E., JARAMILLO, J.J., CARDONA, C.A., Comparison of feedstocks and technologies for biodiesel production: An environmental and techno-economic evaluation, Renewable Energy, 69, 2014, 479-487. https://doi.org/10.1016/j.renene.2014.03.058

8.GUldhe, A., SINGH, B., MUTANDA, T., PERMAUl, K., \& BUX, F. (2015). Advances in synthesis of biodiesel via enzyme catalysis: Novel and sustainable approaches. Renewable and Sustainable Energy Reviews, 41, 1447-1464. https://doi.org/10.1016/j.rser.2014.09.035

9. WANG, Y., OU, S., PENGZHAN, L., XUE, F., TANG, S., Comparison of Two Different Processes to Synthesize Biodiesel by Waste Cooking Oil, Journal of Molecular Catalysis A: Chemical, 252(1-2), 2006, 107-112. https://doi.org/10.1016/j.molcata.2006.02.047

10. *** The State of Food and Agriculture, Biofuels: prospects, risks and opportunities. FAO, 2008.

11.LEUNG, D.Y.C., WU, X., LEUNG, M.K.H., A review on biodiesel production using catalyzed transesterification, Applied Energy, 87(4), 2010, 1083-1095.

https://doi.org/10.1016/j.apenergy.2009.10.006

12. MAZUMDAR, P., DASARI, S.R., BORUGADDA, V.B., SRIVASATAVA, G., SAHOO, L., GOUD, V., Biodiesel production from high free fatty acids content Jatropha curcas L. oil using dual step process, Biomass Conversion and Biorefinery, 3, 2013, 361-369.

https://doi.org/10.1007/s13399-013-0077-3

13. *** From SUS to centistokes annex at different temperatures:

https://www.engineeringtoolbox.com/viscosity-converter-d_413.html (accessed on 18/4/2020)

14. APOSTOLAKOU, A.A., KOOKOS, I.K., MARAZIOTI, C., ANGELOPOULOS, K.C., Technoeconomic analysis of a biodiesel production process from vegetable oils, Fuel Processing Technology, 90(7-8), 2009, 1023-1031

https://doi.org/10.1016/j.fuproc.2009.04.017

15.*** Land prices in Lebanon: https://www.globalpropertyguide.com/Middle-East/Lebanon/PriceHistory (accessed on 24/5/2020)

16. RUI, Z., METZ, P., REYNOLDS, D.B., CHAN, G., ZHOU, X., Historical pipeline construction cost analysis, International Journal of Oil Gas and Coal Technology, 4(3), 2011, 244 - 263.

https://doi.org/10.1504/IJOGCT.2011.040838

17.FORTENBERY, T.R., Biodiesel Feasibility Study: An Evaluation of Biodiesel Feasibility in Wisconsin, Staff Papers 12629, University of Wisconsin-Madison, Department of Agricultural and Applied Economics, 2005. https://doi.org/10.22004/ag.econ.12629

18.***Electricity of Lebanon:

http://www.edl.gov.lb/page.php?pid=39\&lang=en (accessed on 27/5/2020)

Manuscript received: 22.09 .2020 